\title{
Micro Ball End Milling of Titanium Alloy Using a Tool with a Microstructured Rake Face*
}

\author{
Toshiyuki OBIKAWA** and Bunji KANI** \\ ${ }^{* *}$ Institute of Industrial Science, The University of Tokyo \\ 4-6-1 Komaba, Meguro-ku, Tokyo 153-8505, Japan \\ E-mail: obikawa@iis.u-tokyo.ac.jp
}

\begin{abstract}
Many parts and structures for aerospace engineering, marine engineering, bioengineering, etc. are made of titanium alloy because of its excellent physical, chemical, biological and mechanical properties. These days, bio and medical technologies have developed, so more precise and smaller parts of this alloy are required to be machined. However, end milling of this alloy is not easy though many different types of coated end mills have been developed. In this paper, a micro ball end mill with a microstructured rake face was fabricated using focused iron beam irradiation. Then, the effects of different microstructured rake faces on cutting forces of titanium alloy Ti-6Al-4V were experimentally investigated for better machining conditions of this alloy. As a result, it was found that some particular types of microstructured rake faces reduced the cutting forces effectively.
\end{abstract}

Key words: Titanium Alloy, Micro Ball End Mill, Microstructured Rake Face, Cutting Force, Chip Formation

\section{Introduction}

Titanium alloy has been widely applied to aero-engines, fuselages, marine structures, artificial joints, implants, etc. because of its high specific strength, superplasticity, corrosion resistance, biocompatibility, and other excellent physical, chemical, biological and mechanical properties. Nowadays, machining small parts and elements of this alloy with rather complicated configurations is increasingly required in biomedical engineering, microsystems and various fields of microengineering [1]. It is, however, not easy to end-mill this alloy efficiently at higher cutting speeds because there is only a few data of machinability reported so far for precise micromachining of this alloy with a small or miniature tool $[2,3]$.

Using a coated tool does not always improve tool life in end milling of this alloy. It was recently reported that some particular coated tools show high performances in end milling titanium alloy at certain cutting conditions [4,5]. Nevertheless, there are strong requirements for improving the machinability of titanium alloys from various technological points of view.

Some special cutting technologies, such as rotary cutting [6], cutting using high pressure coolant [7], air jet assisted machining [8], etc. have been often applied to machining titanium alloy for extending tool life at higher cutting speeds. Unfortunately, these machining methods are not able to be used for micro end milling with a miniature tool except cryogenic machining [9] and laser assisted micro end milling [10]. Numerical analysis of machining of this alloy [11], e.g., finite element modeling of end milling of the alloy [12] could be applied to the optimization of the cutting conditions for micro ball end milling with a miniature tool.

*Received 2 July, 2012 (№. 12-0281) [DOI: 10.1299/jamdsm.6.1121]

Copyright $\odot 2012$ by JSME 
Quite recently, it was found that microstructured rake face are effective in reducing the friction force and the coefficient of friction at the tool face when they were applied to machining aluminum alloys A5052 [13,14] and A6061-T6 [15], in which the two aluminum alloys showed different reduction maps of cutting forces with respect to cutting speed. These facts suggest that some microstructured faces could improve tribological behavior in metal machining of other workpiece materials.

In this paper, micro ball end mills with different types of microstructured rake faces were fabricated using focused iron beam (FIB) irradiation. Then, they were applied to machining titanium alloy Ti-6Al-4V. The chip forming processes were visualized using a high speed camera. The effects of different types of microstructured rake faces on changes in the cutting forces and chip flow were investigated and discussed for improving the performance of micromachining of the titanium alloy.

\section{Experimental method}

Micro end milling of titanium alloy Ti-6Al-4V was conducted with an uncoated ball end mill on a desktop milling machine placed on a vibration free table. The experimental setup for this study and a schematic of machining experiment are shown in Figs. 1 and 2, respectively. A workpiece of Ti-6Al-4V was fixed on a piezoelectric dynamometer for measuring cutting forces. A high speed camera and lighting apparatus were set at a proper position to take pictures of chip formation during micromilling processes. Cutting conditions are as follows: dry machining without cutting fluid, tool rotational speed $\omega=$ $6000-18000 \mathrm{~min}^{-1}$, the axial depth of cut $a_{\mathrm{p}}=100 \mu \mathrm{m}$, the radial depth of cut (cross feed) $a_{\mathrm{e}}$ $=25-100 \mu \mathrm{m}$ and feed rate $f=3.2-12.8 \mu \mathrm{m} /$ tooth.

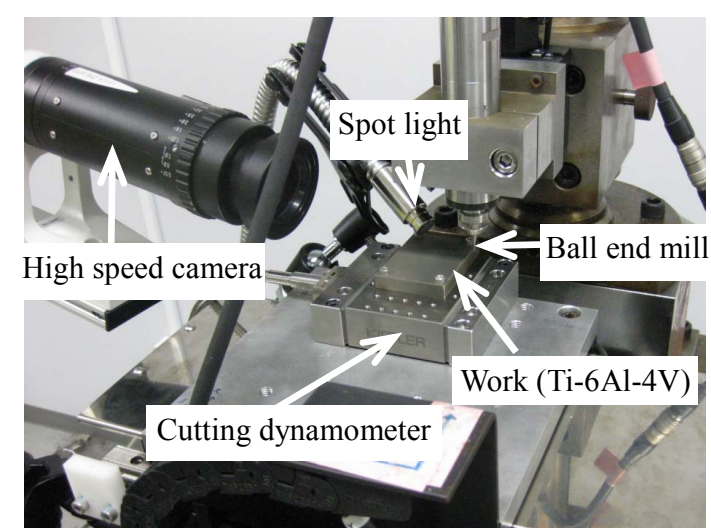

Fig. 1 Experimental setup.

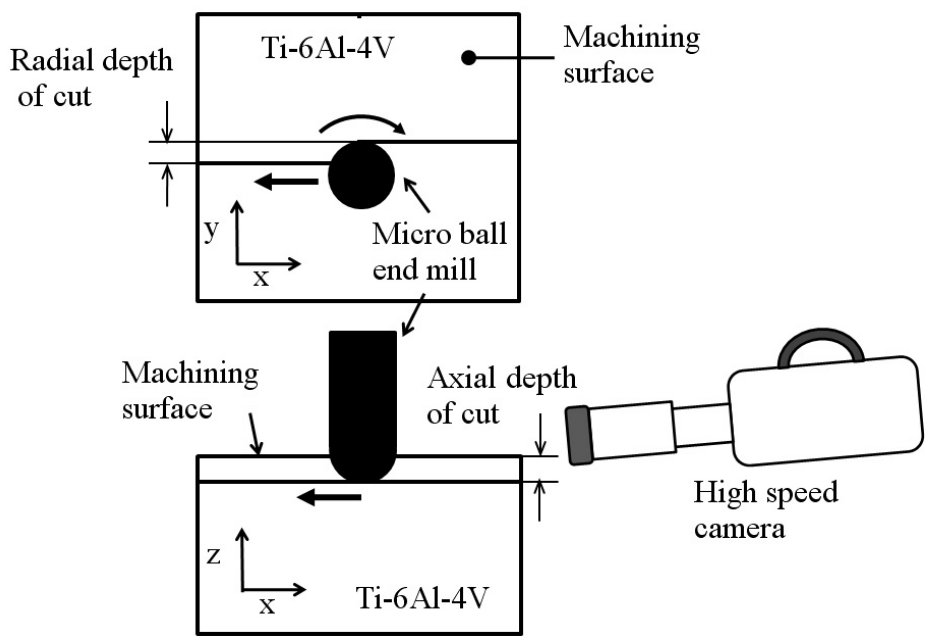

Fig. 2 Schematic of machining experiment. 
A tooth of a two flute ball end mill with nose radius $0.5 \mathrm{~mm}$ and helix angle $30^{\circ}$ was ground away with proper relief angles so that only a tooth with a microstructured rake face would be engaged in end milling. A ball end mill with only a tooth and an area to be microstructured are shown in Fig. 3. Four different arrangements of grooves in black for microstructured faces called "horizontal," "vertical," "parallel" and "perpendicular" types are shown in Fig. 4. Both the width and interval of grooves were set to be $5 \mu \mathrm{m}$. They were fabricated at the microstructured area using raster scanning of FIB irradiation. At the horizontal and vertical types of microstructured rake faces, grooves were parallel to the radial and axial directions of an end mill, respectively. In contrast, at the parallel and perpendicular types of microstructured faces, they were made along the directions approximately parallel and perpendicular to the cutting edge engaged in end milling, respectively.

Changes in the three components of cutting forces in feed, cross feed and axial directions $F x, F y$ and $F z$ were measured using a piezoelectric dynamometer with a force threshold of $0.002 \mathrm{~N}$, which was much smaller than the maximum cutting forces measured. According to the above cutting conditions, cutting time per tooth was of the order of $1 \mathrm{~ms}$. Thus, cutting forces varied at a very high frequency of the order of $1 \mathrm{kHz}$, which is lower than the natural frequency of the dynamometer $4 \mathrm{kHz}$. The cutting forces measured for microstructured tools were compared with those for a not structured tool, which will be called "not-structured" below.

In addition to measuring cutting forces, chip formation process was investigated from its snap shots taken using a digital high speed camera. The camera was positioned to view the chip formation towards the feed direction as shown in Fig. 2. 15000 frames were taken per second at shutter speed $1 / 20000 \mathrm{~s}$; when the tool rotational speed is $12000 \mathrm{~min}^{-1}$ or 200

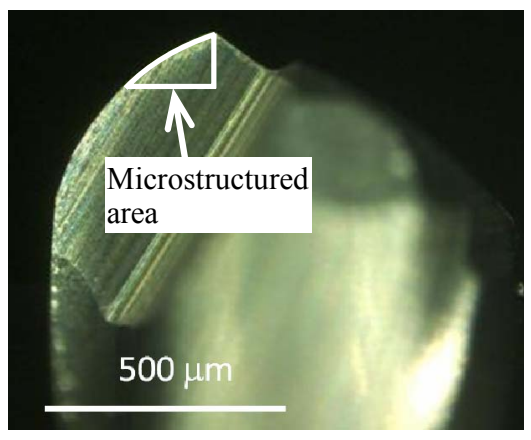

Fig. 3 A tool face to be microstructured.

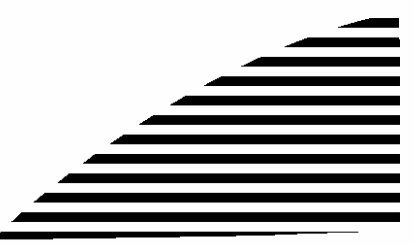

(a) Horizontal

(c) Parallel

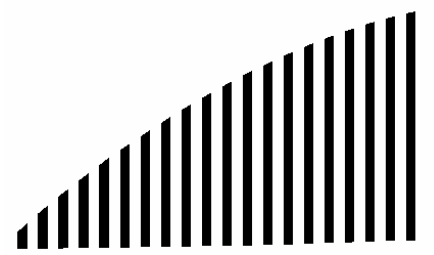

(b) Vertical

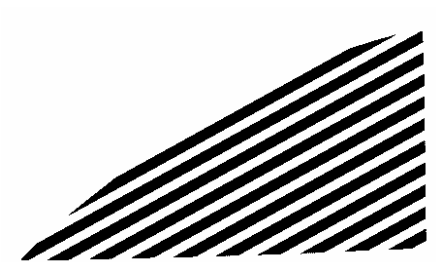

Fig. 4 Four different arrangements of microgrooves for microstructured faces. 
$\mathrm{s}^{-1}$ and the cutting time per tooth is $1 \mathrm{~ms}$, for example, 75 frames were taken per tool revolution and 15 frames during a cut for around $1 \mathrm{~ms}$. The size of a snap shot was $256 \mathrm{x}$ 256 pixels.

\section{Results and discussion}

\subsection{Microstructured rake face}

Four different types of microstructured rake faces called "horizontal," "vertical," "parallel" and "perpendicular" fabricated at the specified area, a magnified view of perpendicular grooves and a micro ball end mill with a microstructured face are shown in Figs. 5, 6 and 7, respectively. The irradiation time of FIB was $80 \mathrm{~min}$.

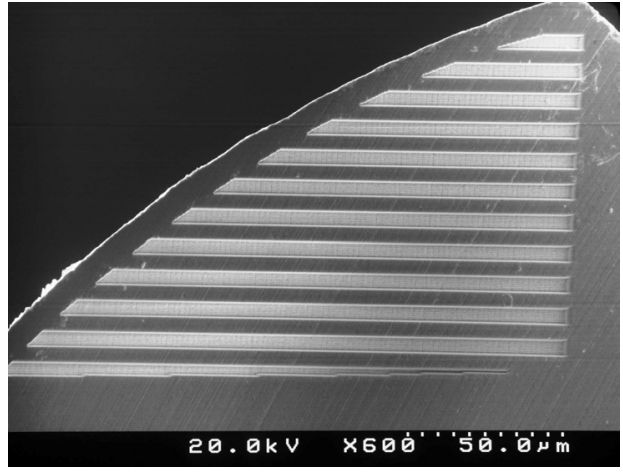

(a) Horizontal

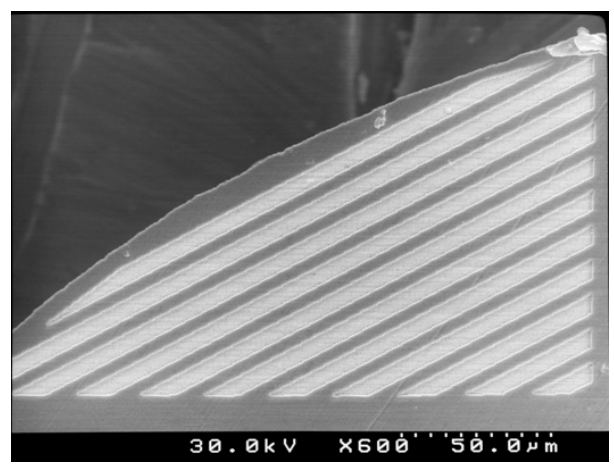

(c) Parallel

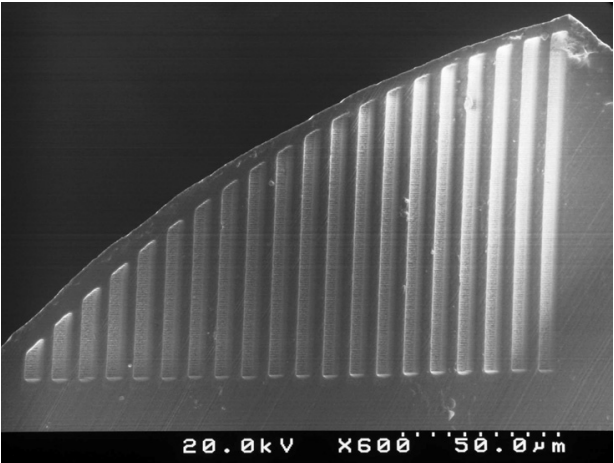

(b) Vertical

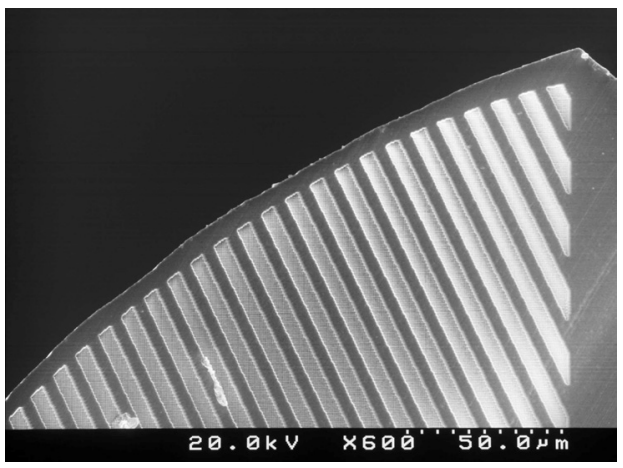

(d) Perpendicular

Fig. 5 Four types of microstructured rake faces.

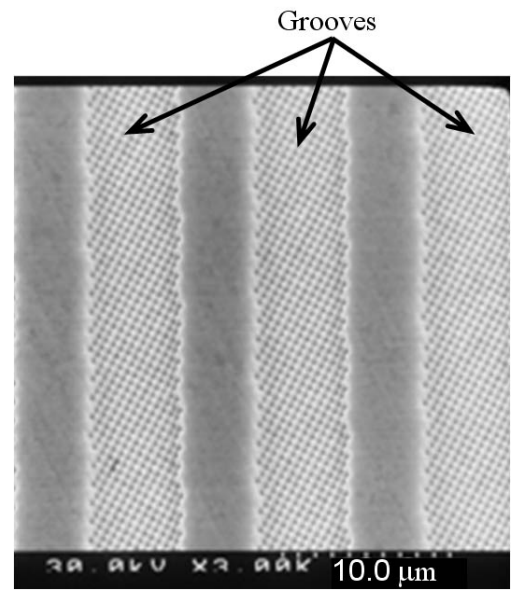

Fig. 6 A magnified view of perpendicular grooves.

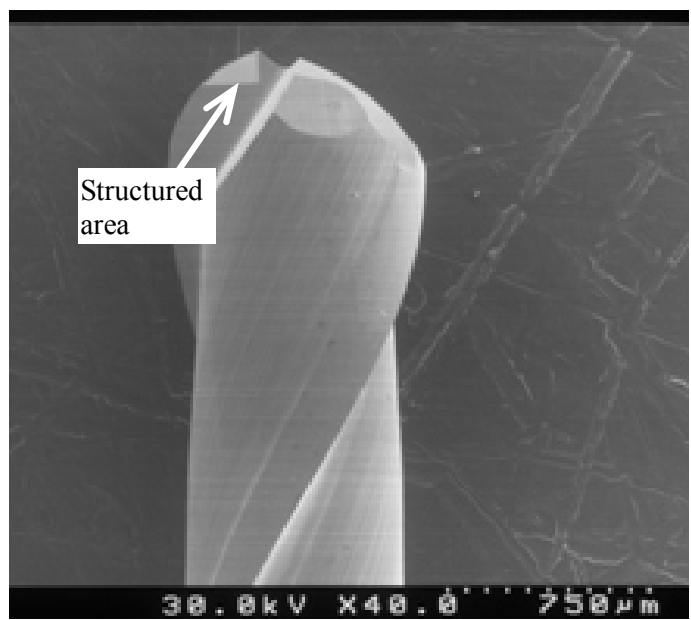

Fig. $7 \mathrm{~A}$ ball end mill with a microstructured face. 
It is seen that the grooves were etched wider than the specified value. According to Fig. 6 a groove is $5.5 \mu \mathrm{m}$ wide and the space between grooves is $4.5 \mu \mathrm{m}$ on an average. Because the scanning lines of FIB were not off-set by the radius of the spot of FIB, the spot size of FIB is roughly estimated to be $0.5 \mu \mathrm{m}$ in diameter. The relationship between the depth of groove and FIB irradiation time is shown in Fig. 8. The groove depth was 1.2, 2.2 and 3.1 $\mu \mathrm{m}$ for irradiation time 40,80 and $120 \mathrm{~min}$, respectively. The depth of groove etched by FIB irradiation is approximately proportional to the irradiation time though the removal rate of cemented carbide decreased a little with time gradually.

\subsection{Cutting forces}

Cutting forces measured for two cuts with a not-structured face of an end mill is shown in Fig. 9. Because time necessary for a single cut was approximately $1 \mathrm{~ms}$, cutting forces causes tool vibration at frequency around $1 \mathrm{kHz}$. For this reason, the maximum cutting force of each component during a cut was obtained by averaging two hundred peak values of the measured force component in a row.

Change in the maximum values of feed, cross-feed and axial forces $F x, F y$ and $F z$ with feed per tooth for the not-structured rake face and the vertical and horizontal types of microstructured rake faces are shown in Figs. 10(a), (b) and (c), respectively. The depth of microgrooves was $2.2 \mu \mathrm{m}$. These figures indicated that the two types of microstructured rake faces are effective in reducing cutting forces.

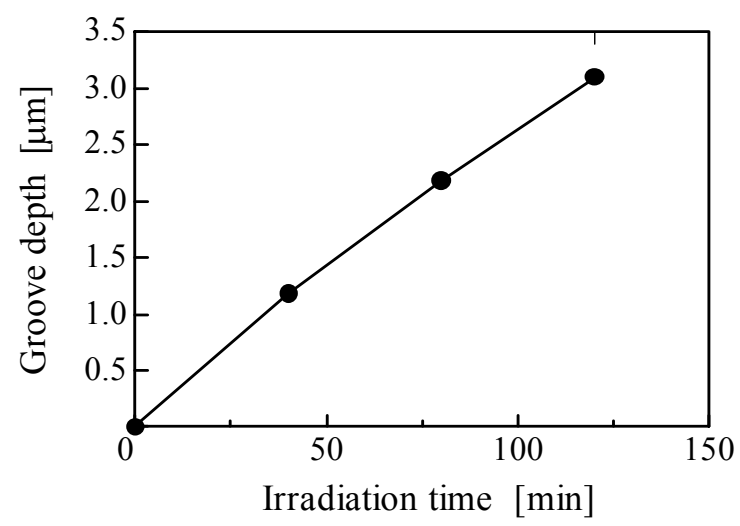

Fig. 8 Relationship between the groove depth and irradiation time.

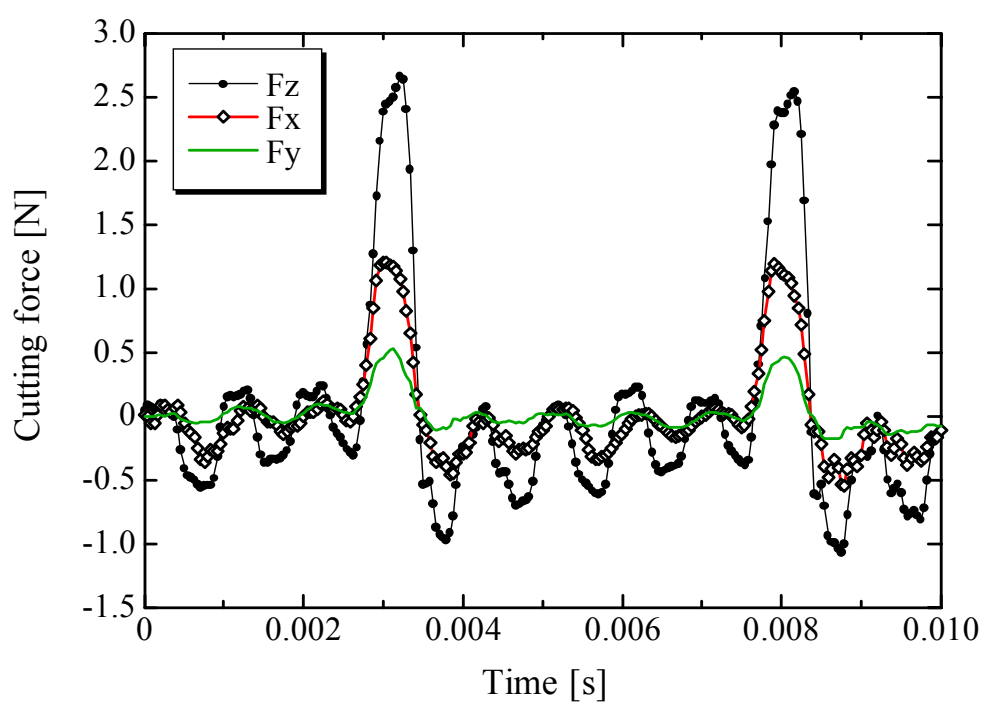

Fig. 9 Changes in cutting forces during 2 turns of an end mill. Cutting conditions: not-structured tool, $\omega=12000 \mathrm{~min}^{-1}, a_{\mathrm{p}}=100 \mu \mathrm{m}, a_{\mathrm{e}}=50 \mu \mathrm{m}, f=6.4 \mu \mathrm{m} /$ tooth. 


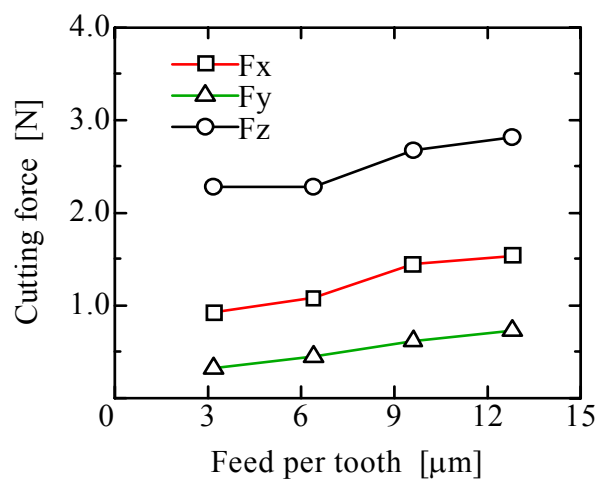

(a) Not-structured

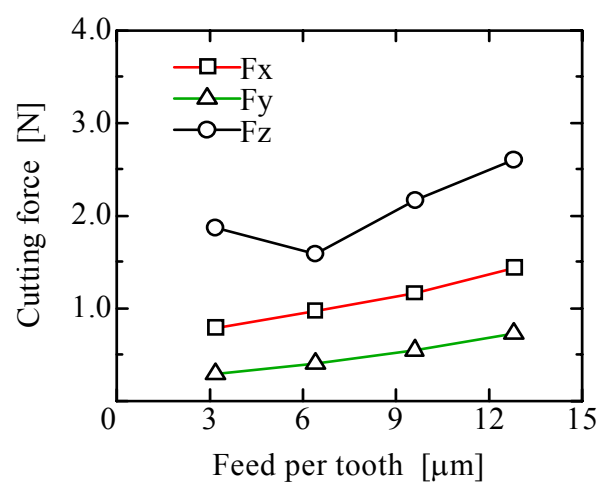

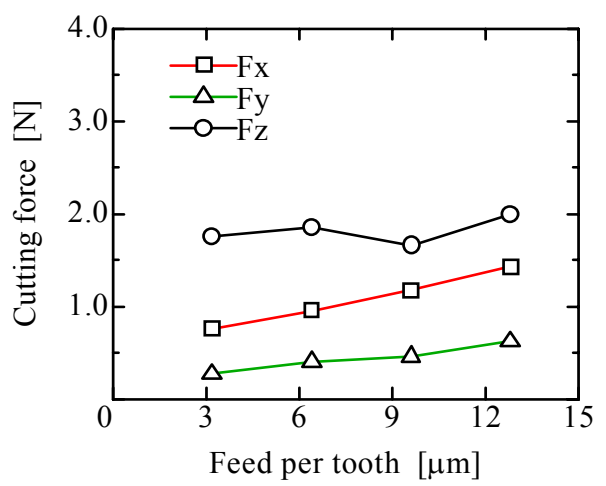

(b) Vertical

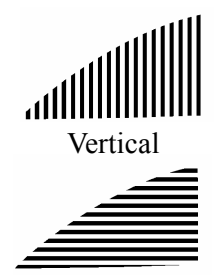

Horizontal

(c) Horizontal

Fig. 10 Changes in cutting forces with feed rate for different microstructured tool faces. Cutting conditions: $\omega=12000 \mathrm{~min}^{-1}, a_{\mathrm{p}}=100 \mu \mathrm{m}, a_{\mathrm{e}}=50 \mu \mathrm{m}, f=$ var.

Changes in the maximum values of cutting forces $F x, F y$ and $F z$ with radial depth of cut and tool rotational speed, which were obtained for the not-structured rake face and the vertical and horizontal types of microstructured rake faces, are shown in Figs. 11 and 12, respectively. The depth of microgrooves was $2.2 \mu \mathrm{m}$. From the results, it was found that the vertical and horizontal types of microstructured faces are effective in reducing cutting forces over a wide range of cutting conditions.

A SEM micrograph of the perpendicular type of microstructured rake face taken after cutting experiment is shown in Fig. 13. There is no visible damage on the tool, but a certain amount of adhesion of the work material is seen along the cutting edge and a side boundary of tool-chip contact area. It was also seen that the work material was smeared at the flank face of the tool. However, there was no strong adhesion of the work material on the grooves.

The mean resultant cutting forces for four feed rates 3.2, 6.4, 9.6 and $12.8 \mu \mathrm{m} /$ tooth was calculated from the maximum values of cutting forces $F x, F y$ and $F z$ for each type of microstructured rake face, and then, normalized with respect to the value for the not-structured rake face. The normalized forces for eight tools with different microstructured faces including not-structured type were compared with each other as shown in Fig. 14. The tool rotational speed was $12000 \mathrm{~min}^{-1}$ and the axial and radial depths of cut were $100 \mu \mathrm{m}$ and $50 \mu \mathrm{m}$, respectively. In this figure and Fig. 15 shown later, term "(d)" means "deep" and indicates that the grooves were etched to $3.1 \mu \mathrm{m}$ in depth by FIB irradiation for $120 \mathrm{~min}$. It is seen that "perpendicular and deep", vertical, "vertical and deep" and horizontal types of microstructured faces reduced the resultant cutting force sharply: reduction by vertical type was as large as $25 \%$. By contrast, the parallel and perpendicular types of microstructured faces increased the resultant cutting force by $6-7 \%$. 


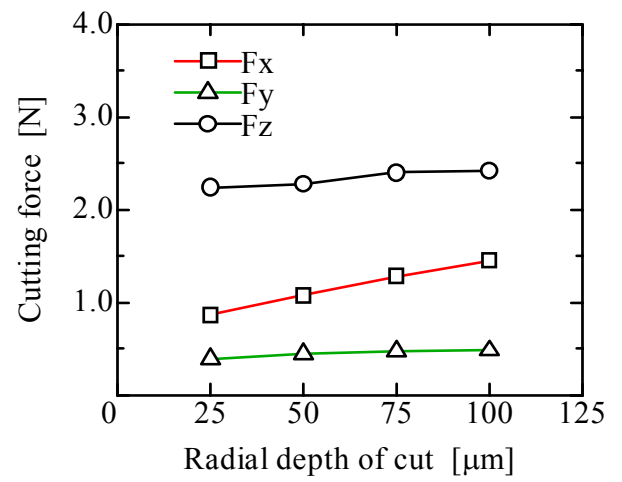

(a) Not-structured

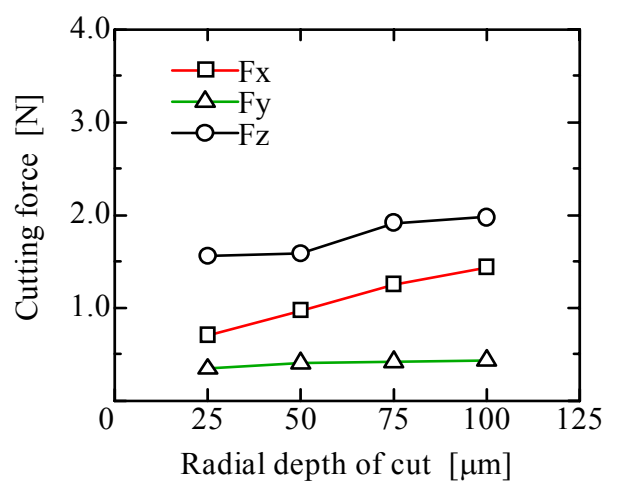

(c) Horizontal

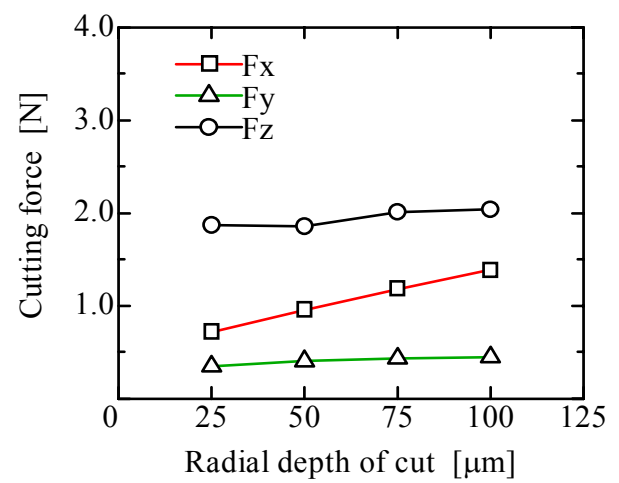

(b) Vertical

Fig. 11 Changes in cutting forces with radial depth of cut for different microstructured tool faces. Cutting conditions: $\omega=12000 \mathrm{~min}^{-1}, a_{\mathrm{p}}=$ var., $a_{\mathrm{e}}=50 \mu \mathrm{m}, f=6.4 \mu \mathrm{m} /$ tooth.

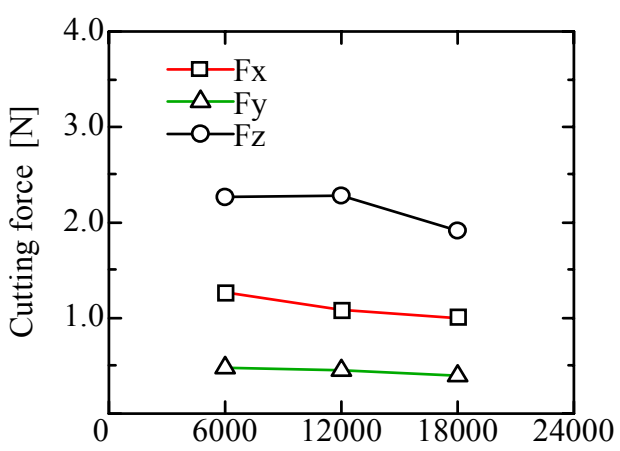

Rotation per minutes [rpm]

(a) Not-structured

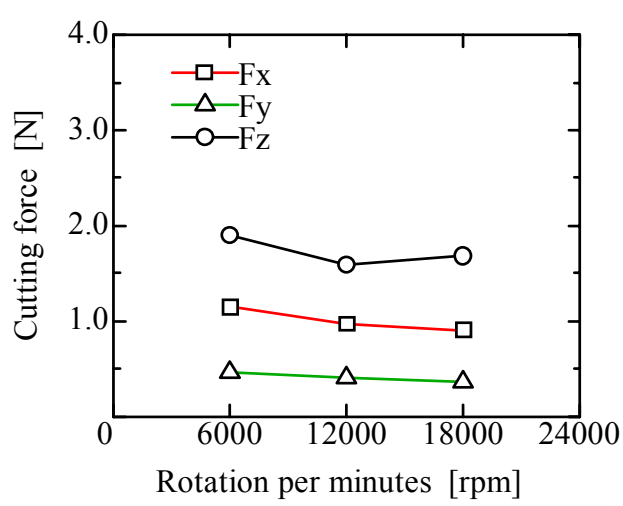

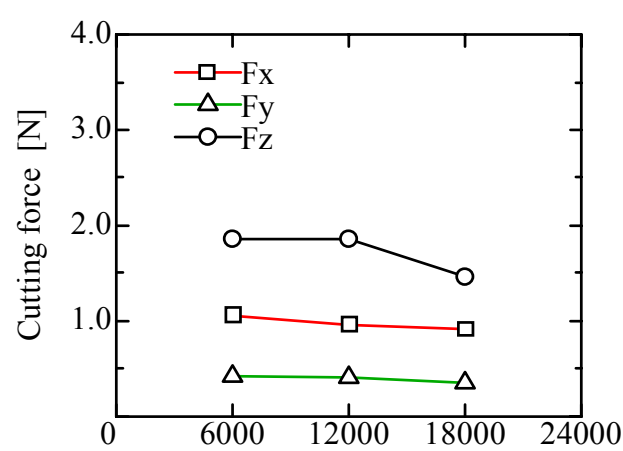

Rotation per minutes [rpm]

(b) Vertical

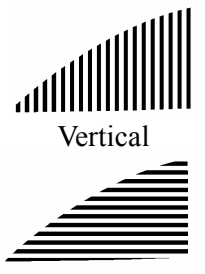

Horizontal

(c) Horizontal

Fig. 12 Changes in cutting forces with tool rotational speed for different microstructured tool faces. Cutting conditions: $\omega=$ var., $a_{\mathrm{p}}=100 \mu \mathrm{m}, a_{\mathrm{e}}=50 \mu \mathrm{m}, f=6.4 \mu \mathrm{m} /$ tooth. 


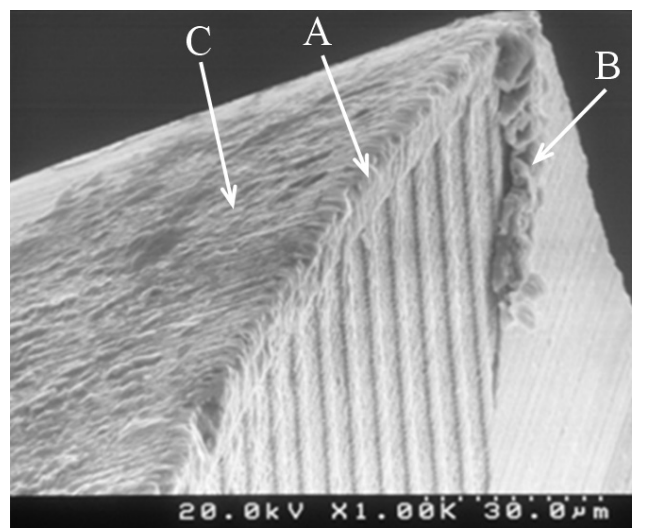

Fig. 13 SEM micrograph of a perpendicular type of microstructured rake face taken after cutting experiment. Adhesion of the work material is seen at the cutting edge (A), a side boundary of tool-chip contact area (B) and the flank face of the tool (C).

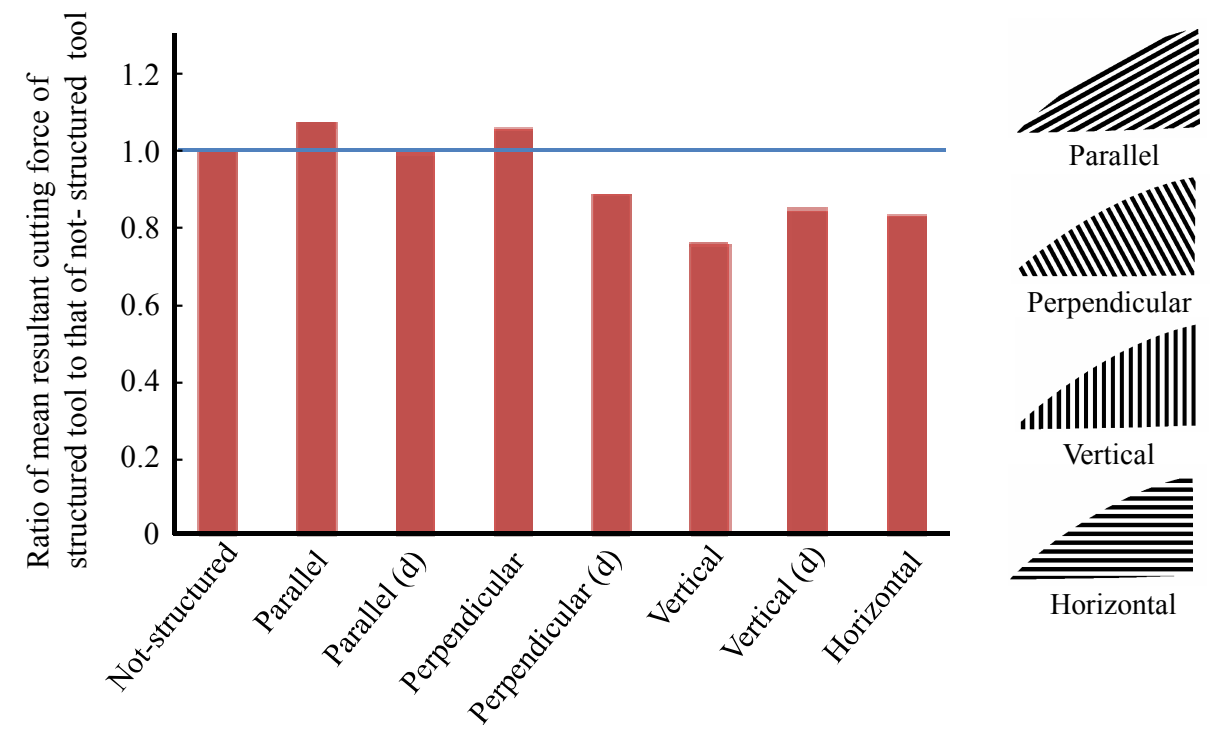

Fig. 14 Mean resultant cutting forces for different microstructured faces normalized with respect to that for a not-structured tool. Cutting conditions: $\omega=12000 \mathrm{~min}^{-1}, a_{\mathrm{p}}=100 \mu \mathrm{m}, a_{\mathrm{e}}=50 \mu \mathrm{m}$ and $f=$ var.

Next, the mean resultant cutting forces for four radial depths of cut 25, 50, 75 and 100 $\mu \mathrm{m}$ was calculated for each type of microstructured rake face. Then, it was normalized with respect to the value for the not-structured rake face and compared with those for other different types of microstructured rake faces and not-structured rake face as shown in Fig. 15. Although the parallel and perpendicular types of microstructured faces increased the resultant cutting force by about $10 \%$, "perpendicular and deep", vertical, "vertical and deep" and horizontal types of microstructured faces effectively reduced the resultant cutting force by $15-20 \%$. Generally, deeper grooves are likely to provide smaller cutting forces. Therefore, if grooves are much deeper than $3.1 \mu \mathrm{m}$, the parallel type of microstructured rake face could reduce cutting forces by around $20 \%$.

According to the results of reference [15], grooves parallel to the cutting edge were effective in reducing cutting forces and the coefficient of friction in orthogonal high speed machining of aluminum alloy though the depth of grooves was $1 \mu \mathrm{m}$. However, this finding for orthogonal machining does not seem to be directly applied to micro ball end milling of titanium alloy at relatively low cutting speed about $10-20 \mathrm{~m} / \mathrm{min}$ and very small feed per 


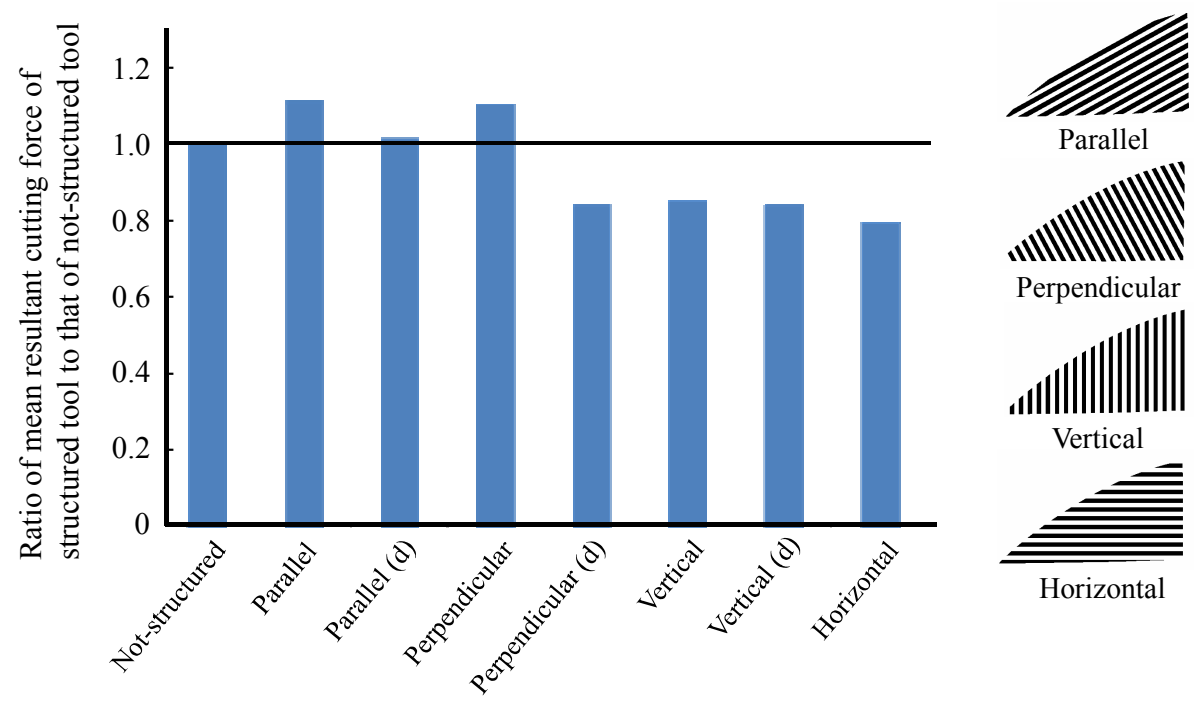

Fig. 15 Mean resultant cutting forces for different microstructured faces normalized with respect to that for a not-structured tool. Cutting conditions: $\omega=12000 \mathrm{~min}^{-1}, a_{\mathrm{p}}=100 \mu \mathrm{m}, f=6.4 \mu \mathrm{m} /$ tooth and $a_{\mathrm{e}}=$ var.

tooth about 5-10 $\mu \mathrm{m}$, in which a chip forms obliquely to the cutting edge at a particular chip flow angle, side curl as well as up curl under the mechanism of three dimensional machining.

\subsection{Chip formation}

A snap shot of chip formation using a tool with the horizontal type of microstructured rake face is shown in Fig. 16. It was clearly seen that a partially formed chip, which was not long enough to cover the microstructured area, was sliding over the microgrooves. Snap shots of longer chips forming with the two different microstructured rake faces are shown in Fig. 17. Chips were not so clear because the tool face was out of focus by rotating from the focused position of Fig. 16. Nevertheless, it was obvious that chip flow directions for the vertical and horizontal types of microstructured rake faces were quite different. Namely, a chip produced using a tool with a particular type of microstructured face was forced to change its flow direction.

The tool-chip contact length is short for machining titanium alloy compared with machining carbon steels, aluminum alloys, etc. Localized shear along the shear plane and

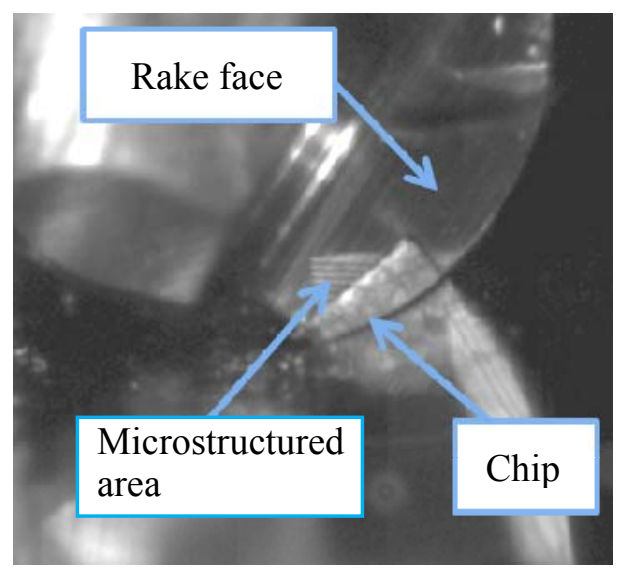

Fig. 16 A snap shot of chip formation for the horizontal type of microstructured face. Cutting conditions: $\omega=12000 \mathrm{~min}^{-1}, a_{\mathrm{p}}=100 \mu \mathrm{m}, a_{\mathrm{e}}=100 \mu \mathrm{m}, f=6.4 \mu \mathrm{m} /$ tooth 


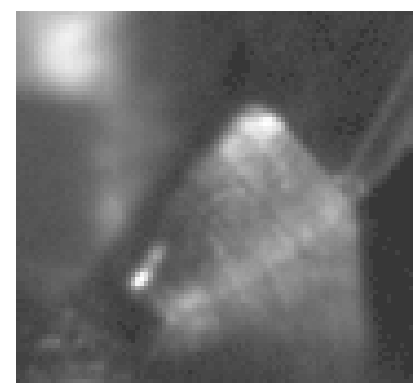

(a) Vertical

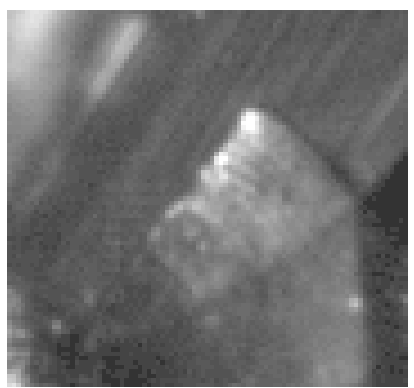

(b) Horizontal

Fig. 17 Snapshots of longer chips forming for two different types of microstructured faces. Cutting conditions are the same as those in Fig. 16.

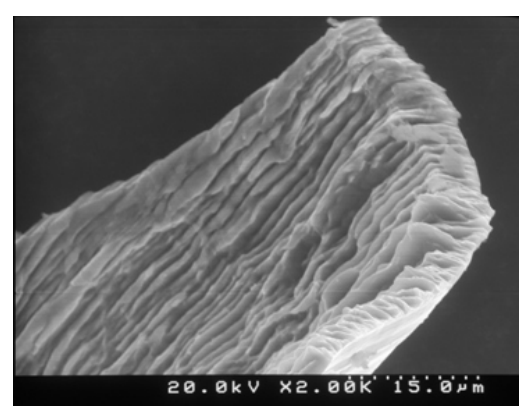

Fig. 18 Chip morphology.

resulting serrated chip formation are main reasons for the short contact length, which was predicted by finite element modeling of machining titanium alloy [11]. The morphology of a chip produced by cutting experiment is shown in Fig. 18. It is seen that although the chip was very thin, the irregular surface with deep serration was produced during chip formation.

The mechanism of serrated chip formation with the short contact length was discussed based on grid deformation at the chip side surface experimentally obtained and change in temperature distribution calculated for a cycle of serrated chip formation [16]. According to these references, the tool-chip contact length in machining titanium alloy is of the order of the undeformed chip thickness. Therefore, change in chip formation mechanism involving chip flow direction and side and up curl curvatures is necessary for large reduction of cutting forces because the further reduction of the tool-chip contact length is not easy to occur. The horizontal and vertical types of microstructured faces must have a definite influence on the chip flow direction because the chip flows across the microgrooves obliquely. In contrast, the parallel and perpendicular types of microstructured faces are not likely to change chip flow direction as far as the depth of microgrooves is not deep.

\section{Conclusions}

Ball end milling of titanium alloy was carried out using tools with the four different types of microstructured rake face, which were fabricated by FIB irradiation. It was found that the vertical and horizontal types of microstructured rake faces reduced cutting forces most effectively though the microgrooves were not deeper that $3.1 \mu \mathrm{m}$. The investigation of chip forming processes using a high speed camera showed that the microgrooves at the rake face could change the chip flow direction, resulting in the reduction of cutting forces. 


\section{References}

(1) Liu, K., Waumans, T., Peirs, J. Reynaerts, D., Precision manufacturing of key components for an ultra miniature gas turbine unit for power generation, Microsystem Technology, Vol. 15, (2009), pp. 1417-1425.

(2) Suzuki, T., Maruoka, T., Kaneko, H., Takahashi, I., Anzai, M., Hirai S., Investigation of the optimum cutting conditions in high speed milling of titanium alloy, Proceedings of the Kanto Branch's Joint Conference, JSME, Saitama city, (2007), pp. 29-30 (in Japanese).

(3) Obikawa, T., Anzai, M., Egawa, T., Narutaki, N., Shintani, K., Takeoka, E., High speed machining: a review from a viewpoint of chip formation, Advanced Materials Research, 188 (2011), pp. 578-583.

(4) Özel, T., Sima, M., Srivastava, A.K., Kaftanoğlu, B., Investigations on the effects of multi-layered coated inserts in machining $\mathrm{Ti}-6 \mathrm{Al}-4 \mathrm{~V}$ alloy with experiments and finite element simulations, CIRP Annals-Manufacturing Technology, Vol. 59, (2010), pp. 77-82.

(5) Basturk, S., Senbabaoglu, F., Islam, C., Erten, M., Lazoglu, I., Gulmez, T., Titanium machining with new plasma boronized cutting tools, CIRP Annals-Manufacturing Technology, Vol. 59, (2010), pp. 101-104

(6) Lei, S., Liu, W., High-speed machining of titanium alloys using the driven rotary tool, International Journal of Machine Tools and Manufacture, Vol. 42, (2002), pp. 653-661.

(7) Ezugwu, E.O., Bonney, J., Da Silva, R.B., Machado, A.R., Ugwoha, E., High productivity rough turning of Ti-6Al-4V alloy with flood and high-pressure cooling, Tribology Transaction, Vol. 52, (2009), pp. 395-400.

(8) Obikawa, T., Funai, K., Kamata, Y., Air jet assisted machining of titanium alloy, Journal of Advanced Mechanical Design, Systems and Manufacturing, 5, 2 (2011) pp. 139-149.

(9) Venugopal K.A., Paul S., Chattopadhyay A.B., Growth of tool wear in turning of Ti-6Al-4V alloy under cryogenic cooling, Wear, Vol. 262, (2007), pp. 1071-1078.

(10) Shelton, J.A., Shin, Y.C., Comparative evaluation of laser-assisted micro-milling for AISI 316, AISI 422, TI-6AL-4V and Inconel 718 in a side-cutting configuration, Journal of Micromechanics and Microengineering, Vol. 20, (2010) AN075012.

(11) Obikawa, T., Usui, E., Computational machining of titanium alloy-Finite element modeling and a few results, Journal of Manufacturing Science and Engineering, Vol. 118, (1996) pp. 208-215.

(12) Özel, T., Thepsonthi, T., Ulutan, D., Kaftanoğlu, B., Experiments and finite element simulations on micro-milling of Ti-6Al-4V alloy with uncoated and cBN coated micro-tools, CIRP Annals-Manufacturing Technology, Vol. 60, (2011) pp. 85-88.

(13) Sugihara, T., Enomoto, T., Development of a cutting tool with nano/micro-textured surface: Improvement of anti-adhesive effect by considering the texture patterns, Precision Engineering, Vol. 33, (2009), pp. 425-429.

(14) Kawasegi, N., Sugimori, H., Morimoto, H., Morita, M., Hori, I., Development of cutting tools with microscale and nanoscale textures to improve frictional behavior, Precision Engineering, Vol. 33, (2009), pp. 248-254.

(15) Obikawa, T., Kamio, A., Takaoka, H., Osada, A., Micro-texture at the coated tool face for high performance cutting, International Journal of Machine Tools and Manufacture, Vol. 51, (2011), pp. 966-972.

(16) Usui, E., Obikawa, T., Shirakashi, T., Study on machining process of difficult-to-machine materials (2nd report), Journal of the Japan Society of Precision Engineering, Vol. 52, No. 9 (1986), pp. 1623-1630 (in Japanese). 